\title{
Ultra-thin aluminium oxide films deposited by plasma- enhanced atomic layer deposition for corrosion protection
}

\section{Citation for published version (APA):}

Potts, S. E., Schmalz, L., Fenker, M., Díaz, B., Swiatowska, J., Maurice, V., Seyeux, A., Marcus, P., Radnóczi, G., Tóth, L., \& Kessels, W. M. M. (2011). Ultra-thin aluminium oxide films deposited by plasma-enhanced atomic layer deposition for corrosion protection. Journal of the Electrochemical Society, 158(5), C132-C138. https://doi.org/10.1149/1.3560197

DOI:

10.1149/1.3560197

Document status and date:

Published: 01/01/2011

\section{Document Version:}

Publisher's PDF, also known as Version of Record (includes final page, issue and volume numbers)

\section{Please check the document version of this publication:}

- A submitted manuscript is the version of the article upon submission and before peer-review. There can be important differences between the submitted version and the official published version of record. People interested in the research are advised to contact the author for the final version of the publication, or visit the $\mathrm{DOI}$ to the publisher's website.

- The final author version and the galley proof are versions of the publication after peer review.

- The final published version features the final layout of the paper including the volume, issue and page numbers.

Link to publication

\section{General rights}

Copyright and moral rights for the publications made accessible in the public portal are retained by the authors and/or other copyright owners and it is a condition of accessing publications that users recognise and abide by the legal requirements associated with these rights.

- Users may download and print one copy of any publication from the public portal for the purpose of private study or research.

- You may not further distribute the material or use it for any profit-making activity or commercial gain

- You may freely distribute the URL identifying the publication in the public portal.

If the publication is distributed under the terms of Article 25fa of the Dutch Copyright Act, indicated by the "Taverne" license above, please follow below link for the End User Agreement:

www.tue.nl/taverne

Take down policy

If you believe that this document breaches copyright please contact us at:

openaccess@tue.nl

providing details and we will investigate your claim. 


\title{
Ultra-Thin Aluminium Oxide Films Deposited by Plasma-Enhanced Atomic Layer Deposition for Corrosion Protection
}

\author{
S. E. Potts, ${ }^{\mathrm{a}, *, \mathrm{z}}$ L. Schmalz, ${ }^{\mathrm{b}}$ M. Fenker, ${ }^{\mathrm{b}}$ B. Díaz, ${ }^{\mathrm{c}}$ J. Ś Siatowska, ${ }^{\mathrm{c}}$ V. Maurice, ${ }^{\mathrm{c}}$ \\ A. Seyeux,${ }^{c}$ P. Marcus, ${ }^{\mathrm{c}}$ G. Radnóczi, ${ }^{\mathrm{d}}$ L. Tóth, ${ }^{\mathrm{d}}{ }^{,}$and W. M. M. Kessels ${ }^{\mathrm{a}, *, \mathrm{z}}$ \\ ${ }^{a}$ Department of Applied Physics, Eindhoven University of Technology, 5600 MB Eindhoven, The Netherlands \\ ${ }^{b}$ FEM Research Institute, Precious Metals \& Metals Chemistry, 72525 Schwäbisch Gmünd, Germany \\ ${ }^{c}$ Laboratoire de Physico-Chimie des Surfaces, CNRS (UMR 7045), École Nationale Supérieure de Chimie de Paris \\ (Chimie ParisTech), 75005 Paris, France \\ ${ }^{d}$ Research Institute for Technical Physics and Materials Science, H-1525 Budapest, Hungary
}

\begin{abstract}
We have employed plasma-enhanced and thermal atomic layer deposition (ALD) within the temperature range of $50-150^{\circ} \mathrm{C}$ for the deposition of ultra-thin $(10-50 \mathrm{~nm}) \mathrm{Al}_{2} \mathrm{O}_{3}$ films on $100 \mathrm{Cr} 6$ steel and aluminium $\mathrm{Al} 2024-\mathrm{T} 3$ alloys. $\left[\mathrm{Al}\left(\mathrm{CH}_{3}\right)_{3}\right]$ was used as the precursor with either an $\mathrm{O}_{2}$ plasma or water as co-reactants. Neutral salt spray tests showed that the thicker films offered the best corrosion-resistance. Using cyclic voltametry, the $50 \mathrm{~nm}$ films were found to be the least porous $(<0.5 \%)$. For $10 \mathrm{~nm}$ thick films, plasma-enhanced ALD afforded a lower porosity and higher film density than thermal ALD. ToF-SIMS measurements on 100Cr6 showed that the main 'bulk' of the films contained very few impurities, but $\mathrm{OH}$ and $\mathrm{C}$ were observed at the interfaces. TEM confirmed that the films were conformal on all substrates and the adhesion was excellent for the films deposited by plasma-enhanced ALD but not for thermal ALD, as delamination was observed. On the basis of these and other results, the prospects of the application of ALD films for corrosion protection, and the use of plasma-enhanced ALD to promote their nucleation, is discussed.

(C) 2011 The Electrochemical Society. [DOI: 10.1149/1.3560197] All rights reserved.
\end{abstract}

Manuscript submitted November 19, 2010; revised manuscript received January 27, 2011. Published March $23,2011$.

Corrosion is a persistent problem for many modern high-precision applications, such as automotive ${ }^{1}$ and aerospace ${ }^{2-4}$ or speciality gas handling. ${ }^{5-8}$ Components for these applications require many high-purity precision parts and instruments, which are commonly manufactured from steel or aluminium alloys. As such, these parts need to be protected by dense and defect-free coatings to prevent corrosion. Ideally, the coatings should be ultra-thin and form a complete sealing barrier to prevent contact between the alloy substrates and the surrounding electrolytes or corrosive gases in the environment. Deposition methods used for such films have included physical vapour deposition (PVD) ${ }^{9,10}$ and chemical vapour deposition (CVD). ${ }^{11,12}$ In particular, plasma-assisted CVD has been of interest, ${ }^{13-15}$ as this allows for deposition at temperatures lower than are typical for CVD, which is beneficial when the substrates are temperature-sensitive, such as heat-treated industrial alloys.

Atomic layer deposition (ALD) is potentially an ideal candidate for this thin $(<100 \mathrm{~nm})$ film application, as it gives high-quality films with excellent conformality, and provides precise thickness control, ${ }^{16}$ which arises from the sequential alternate dosing of metal halide or organometallic and non-metal precursors. For metal oxides, water and ozone are popular co-reactants, but recently oxygen plasmas have seen greater potential because of the presence of reactive ionic and radical species therein. The radicals in a plasma provide higher surface reactivity than is possible with thermal energy alone, ${ }^{17-19}$ which allows for depositions at lower substrate temperatures, even down to room temperature. ${ }^{20}$ This is crucial for temperature-sensitive substrates, such as heat-treated mild steel, for example. Also, the presence of ions can lead to mild bombardment of the film (depending on the plasma configuration and conditions), ${ }^{18}$ which contributes to increased density ${ }^{19}$ and can thereby potentially improve the sealing performance of the coatings. An additional benefit of plasma-enhanced ALD is that a higher density of reactive surface groups are obtained compared with thermal ALD. ${ }^{21}$ This, in turn, can lead to the higher growths per cycle; for example, van Hemmen et al. reported a growth per cycle at $150^{\circ} \mathrm{C}$ of $0.12 \mathrm{~nm} /$ cycle for $\mathrm{Al}_{2} \mathrm{O}_{3}$ from $\left[\mathrm{Al}\left(\mathrm{CH}_{3}\right)_{3}\right]$ and an $\mathrm{O}_{2}$ plasma, ${ }^{22}$ whereas where water was the oxygen source, the growth per cycle was $0.09 \mathrm{~nm} /$ cycle in the same reactor.

\footnotetext{
* Electrochemical Society Active Member.

zzE-mail: s.e.potts@tue.nl; w.m.m.kessels@tue.nl
}

Thermal ALD has been employed as a method for depositing corrosion-resistant metal oxide layers onto stainless steel ${ }^{23}$ and aluminium, ${ }^{24}$ which improved the substrates' resistance to acidic and alkaline solutions, respectively. Additionally, the feasibility of layers deposited by ALD as barrier materials has been demonstrated on organic polymer substrates, which also require low deposition temperatures, for use in organic LEDs. ${ }^{25-28}$ It was shown that $\mathrm{Al}_{2} \mathrm{O}_{3}$ deposited by ALD using water, ${ }^{25,26}$ ozone ${ }^{27}$ and an $\mathrm{O}_{2}$ plasma $^{28}$ as the co-reactant could be used to deposit thin films which sealed the substrate. Langereis et al. reported that plasma-enhanced ALD gave $\mathrm{Al}_{2} \mathrm{O}_{3}$ with excellent sealing properties, where the films deposited at room temperature afforded the lowest water vapour transmission rate. ${ }^{28}$ Despite this, to our knowledge, plasma-enhanced ALD has not been employed for the coating of metal alloys for corrosion protection. As such, the primary focus of this article aims to assess the suitability of $\mathrm{Al}_{2} \mathrm{O}_{3}$ deposited by plasma-enhanced ALD, from $\left[\mathrm{Al}\left(\mathrm{CH}_{3}\right)_{3}\right]$ with an $\mathrm{O}_{2}$ plasma, as a protective layer for $100 \mathrm{Cr} 6$ mild steel and aluminium A12024-T3 alloys, in comparison with thermal ALD (using water as the oxygen source).

\section{Experimental}

Atomic layer deposition.- The experiments were carried out on a commercially-built Oxford Instruments OpAL reactor located in a clean-room. It is an open-load system, which operates with a rotary pump. The base pressure was $\sim 1$ mTorr and typical operating pressures were 100-1000 mTorr. Trimethylaluminium, $\left[\mathrm{Al}\left(\mathrm{CH}_{3}\right)_{3}\right]$ (AkzoNobel, purity $>99.9 \%$,) was employed as the aluminium precursor and was held in a stainless steel bubbler at $24^{\circ} \mathrm{C}$. Oxygen and argon (both purity $>99.999 \%$ ) were flowed into the reaction chamber at 50 and $20 \mathrm{sccm}$, respectively, throughout the plasmaenhanced ALD process. Argon alone was used to purge the precursor lines. The substrate temperature was 50,100 or $150^{\circ} \mathrm{C}$. For the thermal ALD process, water (VWR, GBR Rectapur grade, $>99.999 \%$ ) was also held in a water-cooled stainless steel bubbler at $19^{\circ} \mathrm{C}$ to reduce the vapour pressure and prevent overdosing. Only argon $(200 \mathrm{sccm})$ was used as a process gas for the thermal ALD experiments and $150^{\circ} \mathrm{C}$ was the only substrate temperature employed. The cycle times $\left(\left[\mathrm{Al}\left(\mathrm{CH}_{3}\right)_{3}\right]\right.$ - purge - co-reactant purge) are as follows: plasma-enhanced ALD, 0.05-5-4-2 s; thermal ALD, 0.05-5-0.02-10 s. For all ALD processes, the parameters are outlined in Table I. The number of cycles chosen to obtain the 
Table I. The experimental conditions used, and the film thicknesses and refractive indices measured using spectroscopic ellipsometry (SE) on an n-type Si substrate.

\begin{tabular}{|c|c|c|c|c|c|}
\hline $\begin{array}{l}\text { ALD } \\
\text { method }\end{array}$ & $\begin{array}{l}\text { Deposition } \\
\text { temperature } \\
\quad\left({ }^{\circ} \mathrm{C}\right)\end{array}$ & $\begin{array}{l}\text { Number of } \\
\text { ALD cycles }\end{array}$ & $\begin{array}{l}\text { Nominal } \\
\text { thickness } \\
(\mathrm{nm})\end{array}$ & $\begin{array}{c}\mathrm{SE} \\
\text { thickness on } \\
\mathrm{Si}( \pm 0.05 \mathrm{~nm})\end{array}$ & $\begin{array}{c}\mathrm{SE} \\
\text { refractive index } \\
\text { at } 630 \mathrm{~nm}( \pm 0.02)\end{array}$ \\
\hline Plasma-enhanced & 50 & 55 & 10 & 10.3 & 1.56 \\
\hline - & 150 & 76 & 10 & 10.9 & 1.58 \\
\hline - & 150 & 151 & 20 & 20.6 & 1.58 \\
\hline - & 150 & 385 & 50 & 50.9 & 1.62 \\
\hline
\end{tabular}

desired film thicknesses was based on the growths per cycle reported previously in our earlier work (plasma-enhanced ALD: 0.16, 0.14, and $0.13 \mathrm{~nm} /$ cycle at 50,100 , and $150^{\circ} \mathrm{C}$, respectively; thermal ALD with water: $0.09 \mathrm{~nm} /$ cycle at $\left.150^{\circ} \mathrm{C}\right){ }^{20,22}$

Substrates.-100Cr6 steel (Schäffler) and Al2024-T3 aluminium (Messier-Bugatti) alloys were employed as substrates. For the $100 \mathrm{Cr} 6$, fine-ground and lapped surface preparations were investigated and the Al2024-T3 samples had a fine-ground surface finish. The fine-ground surface finish was obtained using a planar grinding machine (Kehren, type RS) using corundum (Tyrolit, 89A461H9AV2) as a grinding medium with lubricant (Hosmac 928). The lapped surface finish was obtained upon further treatment of the fine-ground surfaces using an Elap 400 machine with a water-based diamond suspension ( $\sim 6 \mu \mathrm{m}$, LamPlan Diamant MM342) for $2 \mathrm{~h}$. After preparation, the substrates were dried in compressed nitrogen (99.999\%) and coated in silicon oil (Sigma-Aldrich GmbH, no. 85409). Prior to transportation, the samples were packaged in membrane boxes (Inca S. A. Plastic) to prevent excess movement. Coated samples were also sent in the membrane boxes for analysis. Before deposition, the required substrates were cleaned in an ultrasonic isopropanol (Emplura grade, Merck Chemicals International) bath for $5 \mathrm{~min}$ and then blow-dried in roomtemperature nitrogen. Reference substrates were used in each process, which were $1 / 4100 \mathrm{~mm}$ n-type $\mathrm{Si}(100)$ wafers. These wafers were covered with a thin native oxide $\left(\mathrm{SiO}_{2}, \sim 1.5 \mathrm{~nm}\right)$ layer and did not undergo any additional cleaning steps.

Spectroscopic ellipsometry (SE).-A J. A. Woollam Inc. M2000 rotating compensator ellipsometer on a multi-angle Gonio stage (angles used: $65,70,75$, and $80^{\circ}$ ) was employed to confirm the thickness and refractive index of the films on the reference Si substrates. Modelling was carried out using CompleteEASE software. The model layers comprised $\mathrm{Si}$, native $\mathrm{SiO}_{2}$ and $\mathrm{Al}_{2} \mathrm{O}_{3}$. The $\mathrm{Al}_{2} \mathrm{O}_{3}$ layer was modelled using a Cauchy layer over the wavelength range of $190-1000 \mathrm{~nm}(1.2-6.5 \mathrm{eV})$. Further details on the SE technique and modelling can be found in the literature. ${ }^{29}$

Electrochemical tests.-All electrochemical tests were performed using a 3-electrode system with a Pt counter electrode and a $\mathrm{SCE}$ reference electrode at ambient temperature $\left(\sim 20^{\circ} \mathrm{C}\right)$. The electrolytes were $0.5 \mathrm{M} \mathrm{NaCl}$ for the Al2024-T3 substrates and $0.2 \mathrm{M}$ $\mathrm{NaCl}$ for the $100 \mathrm{Cr} 6$ substrates, prepared with ultra-pure water (resistivity $>18 \mathrm{M} \Omega \mathrm{cm}$ ) and reagent grade chemicals ( $\mathrm{NaCl}$ Analar Normapur analytical reagent VWR BDH Prolabo). These solutions were de-aerated by bubbling argon gas through them for $30 \mathrm{~min}$ prior to the measurements. The $p \mathrm{H}$ was $7.2 \pm 0.2$ prior to the corrosion test. The CV tests were performed afterwards from a cathodic vertex and in a potential range depending on the substrate and its susceptibility to pitting corrosion. All CV curves (including the reverse cathodic scan) were obtained at a scan rate of $1 \mathrm{mV} \mathrm{s}^{-1}$. The electrochemical measurements on $100 \mathrm{Cr} 6$ substrates were performed on polished samples and Al2024-T3 substrates on fine-ground surfaces.

Transmission electron microscopy (TEM).-TEM analysis was carried out using a $200 \mathrm{kV}$ Philips CM20 analytical TEM equipped with an EDS detector. Prior to the analysis, all samples were thinned by a standard mechanical grinding/ion bombardment technique. This involved cutting the substrates, embedding them into a custommade Ti-holder, mechanical grinding and polishing, followed by 10 $\mathrm{keV}$ Ar ion milling. The final step was carried out at lower ion energy of $3 \mathrm{keV}$ in order to decrease the surface damage of the thinned TEM specimens.

Time-of-flight secondary ion mass spectrometry (ToFSIMS).-Elemental depth profiles were obtained using a ToF-SIMS 5 spectrometer (IonTof). The spectrometer was run at an operating pressure of $10^{-9}$ mbar in HC-BUNCHED mode. A pulsed $25 \mathrm{keV}$ $\mathrm{Bi}^{+}$primary ion source was employed for analysis, delivering 1.8 or $0.86 \mathrm{pA}$ of current over a $175 \times 175 \mu \mathrm{m}$ or $100 \times 100 \mu \mathrm{m}$ area for the 50 and $10 \mathrm{~nm}$ thick coatings, respectively. Depth profiling was performed using a $2 \mathrm{keV}$ sputter beam giving a 100 or $82 \mathrm{nA}$ target current over a $400 \times 400 \mu \mathrm{m}$ or $1000 \times 1000 \mu \mathrm{m}$ area for the 50 and $10 \mathrm{~nm}$ thick coatings, respectively. Data acquisition and post-processing analyses were performed using the Ion-Spec software. The profiles were recorded with negative secondary ions, which are more sensitive to fragments originating from oxide matrices.

Neutral salt spray (NSS) testing.-Neutral salt spray tests were performed according to the standard DIN 50021, ISO 9227 but with the deviation that the samples were rinsed in deionised water and dried with a hair dryer (warm, not hot air) before photographs were taken of the samples. The electrolyte was $50 \pm 5 \mathrm{~g} \mathrm{~L}^{-1}(\sim 0.86 \mathrm{M})$ $\mathrm{NaCl}$ with a $p \mathrm{H}$ value in the range of 6.5-7.2. The tests were carried out at a temperature of $35 \pm 2^{\circ} \mathrm{C}$. Photographs were taken of the samples after 2,4 , and $24 \mathrm{~h}$ testing. If no, or only negligible, corrosion products were visible, the samples were transferred back to the salt spray test chamber and the test was continued until significant red rust was visible on the $100 \mathrm{Cr} 6$ steel samples or white rust on the Al2024-T3 substrates, after which the samples were removed from the test chamber.

\section{Results and Discussion}

$\mathrm{Al}_{2} \mathrm{O}_{3}$ films were deposited on industrial alloys using plasmaenhanced and thermal ALD. For the coatings deposited by plasmaenhanced ALD, the corrosion characteristics were tested by conducting a thickness series of films of nominally 10, 20, and $50 \mathrm{~nm}$ on lapped 100Cr6 steel and fine-ground Al2024-T3 substrates at a deposition temperature of $150^{\circ} \mathrm{C}$. Additionally, a temperature series was carried out at temperatures of 50,100 and $150^{\circ} \mathrm{C}$, focussing on $10 \mathrm{~nm}$ thick films. Higher temperatures could not be used due to the heat-treatment of the steel. Coatings deposited by thermal ALD (at $150^{\circ} \mathrm{C}$ only) with thicknesses of 10 and $50 \mathrm{~nm}$ were deposited on $100 \mathrm{Cr} 6$ and Al2024-T3 for comparison with the plasma-enhanced process.

The film thicknesses and refractive indices, measured by SE, are outlined in Table I. These measurements were taken from the n-type Si reference substrate included in the reaction chamber during the depositions. For the samples deposited by plasma-enhanced ALD, 
the thicknesses were measured to be within $1 \mathrm{~nm}$ of the nominal thickness, while for the $50 \mathrm{~nm}$ thick film for thermal ALD, the thickness was $\sim 4 \mathrm{~nm}$ higher than intended. The refractive indices increased slightly with increasing film thickness and deposition temperature, suggesting a better bulk quality material. This is confirmed by previously-reported Rutherford backscattering results, which showed that films deposited at higher temperatures had higher densities, ${ }^{20}$ which was attributed to there being a lower concentration of $\mathrm{OH}$ groups in those films.

$C V$ porosity.-The porosity, which can be thought of as the percentage of uncoated film surface, was measured by cyclic voltametry. ${ }^{30}$ For the films deposited by plasma-enhanced ALD on $100 \mathrm{Cr} 6$, the porosity was highest for the thinnest films, at $\sim 0.6 \%$, with the porosity decreasing with increasing thickness to $0.07 \%$ for $50 \mathrm{~nm}$ thick films (see Fig. 1a). Where thermal ALD was used, the porosity was an order of magnitude higher for the $10 \mathrm{~nm}$ films, suggesting that nucleation and film densification was not as efficient using this process, leaving $3.65 \%$ of the $100 \mathrm{Cr} 6$ surface uncoated. The case was seemingly reversed for the $50 \mathrm{~nm}$ films, although the porosity of the films deposited using thermal ALD varied greatly over the samples, as shown by the error bar; therefore, the porosities of the films deposited by the two techniques were considered equivalent at a thickness of $50 \mathrm{~nm}$. The thicker films have a higher probability of covering surface features more efficiently due to the greater amount of material being deposited. This thickness dependence could possibly be resolved by using a surface pre-treatment.

On Al2024-T3 (Fig. 1b), the porosities were generally significantly higher, suggesting that there were significant nucleation problems for these substrates and/or coating delamination occurring during the electrochemical testing as a result of poor adhesion. However, some of porosity values (for example, 56\%) are unrealistically high to be considered as porosities, which might suggest that dissolution of the film during the measurements was occurring for such a large surface area to be seemingly bare. However, the trend was similar to the $100 \mathrm{Cr} 6$ substrates, where there was a general decrease in porosity with increasing film thickness. Again for the
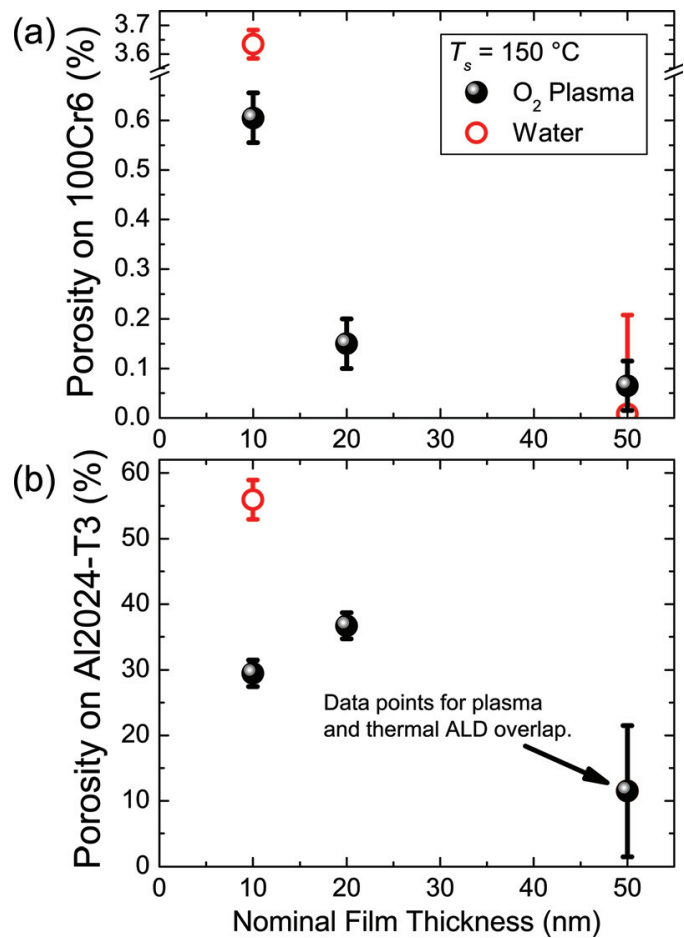

Figure 1. (Color online) Variation of film porosity as a function of film thickness for $\mathrm{Al}_{2} \mathrm{O}_{3}$ films deposited at $150^{\circ} \mathrm{C}$ on (a) lapped $100 \mathrm{Cr} 6$ and (b) fine-ground Al2024-T3. Note the break in the vertical axis for $100 \mathrm{Cr} 6$. thermal ALD, the porosity of the films was higher than the plasmaenhanced method for the $10 \mathrm{~nm}$ thick films ( $\sim 56$ and $\sim 30 \%$, respectively) but equivalent for the $50 \mathrm{~nm}$ thick films $(\sim 10 \%)$.

The temperature series was carried out for $10 \mathrm{~nm}$ thick films deposited by plasma-enhanced ALD (Fig. 2). For 100Cr6 steel, there was an almost linear decrease in the film porosity with increasing deposition temperature. It is known that $\mathrm{Al}_{2} \mathrm{O}_{3}$ films grown at lower temperatures tend to have lower densities, primarily due to the increased incorporation of $\mathrm{OH}$ groups. ${ }^{20,22}$ Such densities leave the film prone to having a higher concentration of defects, therefore higher porosities, through which corroding media can travel. The plasma-enhanced method did, however, give a much lower film porosity (at $150^{\circ} \mathrm{C}$ ) than the corresponding thermal ALD process, which is attributed mainly to the increased film density resulting from the higher reactivity provided by the plasma and the improved nucleation properties of the films. It should be noted that the thermal ALD process was not carried out at deposition temperatures lower than $150^{\circ} \mathrm{C}$ due to the long purge times required when using water; for example, Groner et al. reported necessary water purge times of $180 \mathrm{~s}$ at $33^{\circ} \mathrm{C}^{31}$ At $150^{\circ} \mathrm{C}$, we found that only a $10 \mathrm{~s}$ water purge was necessary for thermal ALD, but for plasma-enhanced ALD, $2 \mathrm{~s}$ was sufficient for all temperatures.

For Al2024-T3 substrates, the opposite trend was observed, whereby the lowest deposition temperatures afforded the lowest film porosities $(\sim 12 \%)$, which almost doubled at $150^{\circ} \mathrm{C}$. However, in a similar manner to the $100 \mathrm{Cr} 6$, the porosity for the thermal ALD films was substantially higher than that for the plasma-enhanced ALD films deposited at $150^{\circ} \mathrm{C}$.

TEM imaging.-Cross-sectional bright field TEM images showed that the $\mathrm{Al}_{2} \mathrm{O}_{3}$ deposited by both plasma-enhanced and thermal ALD were conformal on fine-ground Al2024-T3 (Fig. 3) and lapped 100Cr6 (Fig. 4). For the films deposited by plasma-enhanced ALD on Al2024-T3, the coating was present even in deep cracks in the substrate (Fig. 3), which shows that the $\mathrm{O}_{2}$ plasma radicals can reach down trenches. Radicals formed in a plasma are known to

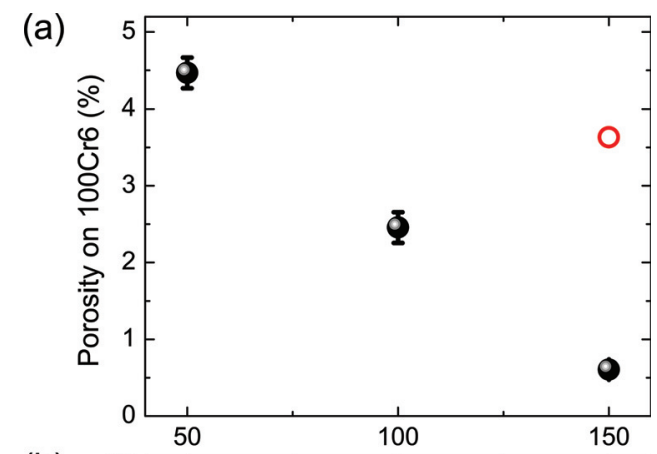

(b)

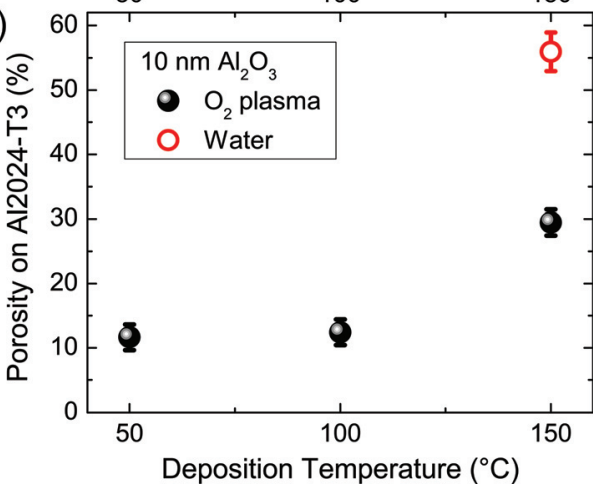

Figure 2. (Color online) Variation of film porosity as a function of deposition temperature for $10 \mathrm{~nm}$ thick $\mathrm{Al}_{2} \mathrm{O}_{3}$ films deposited by plasma-enhanced ALD on (a) lapped $100 \mathrm{Cr} 6$ and (b) fine-ground A12024-T3. The porosity for films deposited by thermal ALD at $150^{\circ} \mathrm{C}$ is given for comparison. 


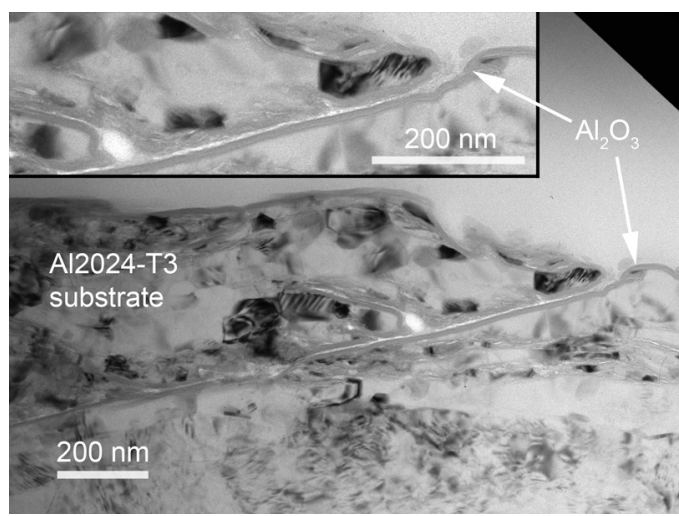

Figure 3. Bright-field TEM image of $\sim 20 \mathrm{~nm} \mathrm{Al}_{2} \mathrm{O}_{3}$ deposited on Al2024$\mathrm{T} 3$ by plasma-enhanced ALD at $150^{\circ} \mathrm{C}$. Inset: close-up of the trench area.

recombine at surfaces, although oxygen radicals have a low recombination probability on metal oxides. ${ }^{19,32}$ Therefore, it is likely that the native oxide on the A12024-T3 allows the high aspect ratio trench to be coated.

For all thermal ALD samples, there was a void present $(\sim 20 \mathrm{~nm})$ between the substrate and coating (filled with glue used in the TEM preparation), suggesting that the $\mathrm{Al}_{2} \mathrm{O}_{3}$ film was not well adhered. The same was the case on 100Cr6 substrates (Fig. 4), where the film was separated from the substrate by $\sim 8 \mathrm{~nm}$. The use of a plasma in the ALD process therefore has a beneficial influence on the adhesion of the film, which can be crucial for the coating's resistance to corrosion.

ToF-SIMS depth profiles.-Time-of-flight secondary ion mass spectroscopy studies were carried out on nominally 50 and $10 \mathrm{~nm}$ thick $\mathrm{Al}_{2} \mathrm{O}_{3}$ films on lapped $100 \mathrm{Cr} 6$ substrates in order to compare the plasma-enhanced and thermal ALD techniques. For the $50 \mathrm{~nm}$ thick samples (Fig. 5), there was no significant difference in the width of the interfacial region between the film and the substrate. This was not unexpected as this width is mostly governed by the roughness of the alloy surface, which causes shadowing effects during sputtering. Consequently, the slight differences in film thickness (Table I) between the plasma-enhanced and thermal ALD processes could not be resolved. In terms of the composition of the interfacial region, the signals of the $\mathrm{FeO}_{2}^{-}$and $\mathrm{CrO}_{2}^{-}$ions were slightly lower for the plasma-enhanced process, suggesting less contamination by the substrate oxide. However, the $\mathrm{C}^{-}$and $\mathrm{OH}^{-}$signals were comparable for both samples. In the bulk of the coatings there was a lower concentration of $\mathrm{OH}$ for the plasma-enhanced process in the later stages of deposition, which is a result of the higher reactivity of the

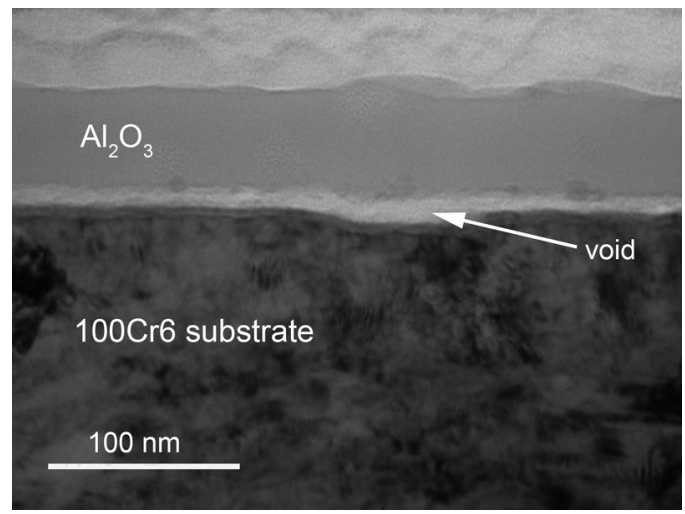

Figure 4. Bright-field TEM image of $\sim 55 \mathrm{~nm} \mathrm{Al}_{2} \mathrm{O}_{3}$ deposited on $100 \mathrm{Cr} 6$ by thermal ALD at $150^{\circ} \mathrm{C}$, showing a void filled with glue, from the TEM sample preparation, between the coating and the substrate.
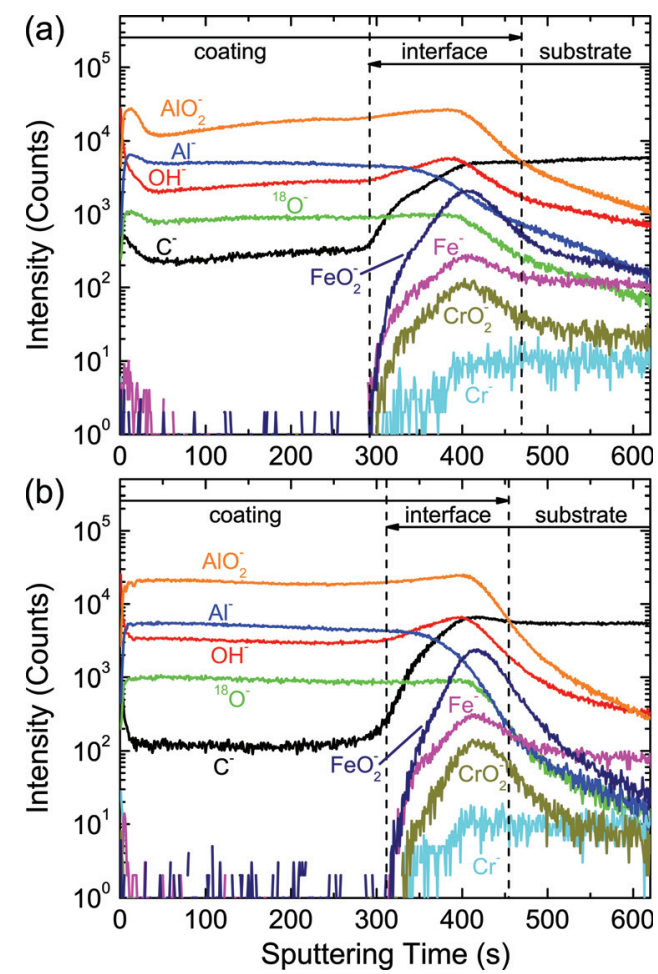

Figure 5. (Color online) ToF-SIMS depth profiles for $50 \mathrm{~nm} \mathrm{Al}_{2} \mathrm{O}_{3}$ deposited at $150^{\circ} \mathrm{C}$ on $100 \mathrm{Cr} 6$ using (a) plasma-enhanced ALD and (b) thermal ALD.

plasma than water in the ALD process, causing film densification when the influence of interfacial contamination decreased. Film densification has been verified by Rutherford backscattering data on $\mathrm{Al}_{2} \mathrm{O}_{3}$ films, which has shown that films with lower $\mathrm{OH}$ concentrations have a higher density, and that films deposited by plasmaenhanced ALD are slightly denser than those deposited by thermal ALD. ${ }^{22}$ Our ToF-SIMS data show that this effect is more sensitive away from the interfacial region. However, the presence of $\mathrm{OH}$ in the films is not necessarily detrimental to the coating efficiency since the lowest porosity was obtained with the $50 \mathrm{~nm}$ thick thermal ALD sample (which contained the more $\mathrm{OH}$ in the bulk of the coating). A similar trend has been observed in the use of $\mathrm{Al}_{2} \mathrm{O}_{3}$ as a protective coating for organic LEDs, ${ }^{28}$ where the films containing more $\mathrm{OH}$ (which were deposited by plasma-enhanced ALD at room temperature) exhibited better moisture-barrier properties than films deposited at higher temperatures.

Regarding the coating surface, Fig. 6 shows that $\mathrm{OH}$ was present further below the surface for the plasma-enhanced ALD samples (up to $\sim 30 \mathrm{~s}$ sputtering) than for the thermal ALD sample $(\sim 10 \mathrm{~s}$ sputtering), although the overall concentration of $\mathrm{OH}$ in the former was lower. This surface variation appears to be related to the $\mathrm{AlO}_{2}$ ion profile (Fig. 5), which shows a hump in the same near-surface region of the plasma-enhanced ALD sample, suggesting a deeper penetration of surface hydroxylation. This could be due to environment-induced modifications occurring during ex situ transfer for sample analysis. It is likely that this is promoted by the higher density of reactive surface sites on the plasma-enhanced ALD samples compared with those deposited by thermal ALD. A higher density of reactive surface groups is a characteristic of plasma-enhanced ALD and is one of the main contributing factors to the higher growths per cycle obtained. ${ }^{21}$

For the $10 \mathrm{~nm}$ thick samples, the difference between the two deposition methods is significantly more prominent (Fig. 7). For the film deposited by plasma-enhanced ALD, a sputtering time of $\sim 400 \mathrm{~s}$ was needed to reach the interface, whereas for thermal ALD, only $110 \mathrm{~s}$ was required (both of these samples were analysed with the same 


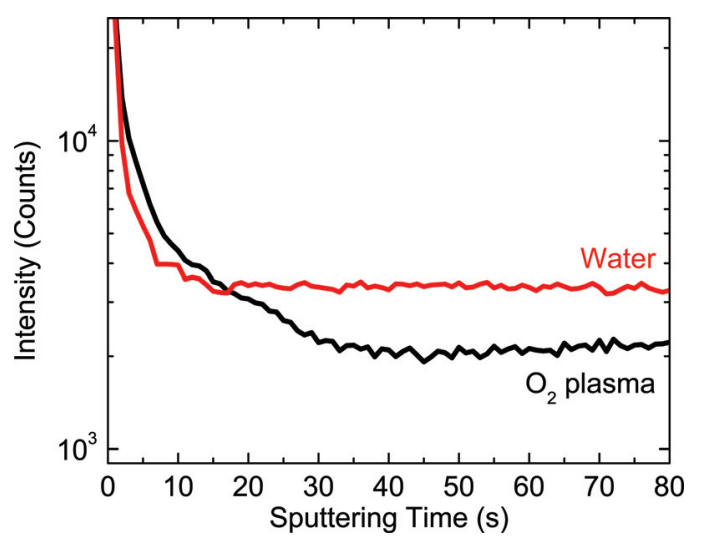

Figure 6. (Color online) ToF-SIMS depth profiles for the $\mathrm{OH}^{-}$species at the surface of the $50 \mathrm{~nm}$ thick $\mathrm{Al}_{2} \mathrm{O}_{3}$ films deposited by plasma-enhanced $\left(\mathrm{O}_{2}\right.$ plasma) and thermal (water) $\mathrm{ALD}$ at $150^{\circ} \mathrm{C}$.

sputtering target $\mathrm{Cs}^{+}$ion current density). This is not due to differing film thicknesses, as the results from the SE measurements (Table I) were very similar, but it suggests that the film deposited by thermal ALD was significantly less dense and, consequently, had a markedly higher sputtering yield. This is likely to be related to the better nucleation afforded by the use of a plasma as a co-reactant, which is also confirmed by the porosity results, therefore leading to denser films in the initial stages of growth. This densification is also supported by the slightly higher intensity of the $\mathrm{Al}^{-},{ }^{18} \mathrm{O}^{-}$and $\mathrm{AlO}_{2}^{-}$ion profiles in the bulk of the plasma-enhanced coating when compared with the thermal process. In both cases, the coating contained $\mathrm{OH}$ and $\mathrm{C}$ originating from environmental contamination and/or from incomplete removal of the precursors used for deposition. The $\mathrm{OH}$ and $\mathrm{C}$ signals were lower for the plasma-enhanced sample, which is also indicative of a denser $\mathrm{Al}_{2} \mathrm{O}_{3}$ layer that is less sensitive to environment-induced
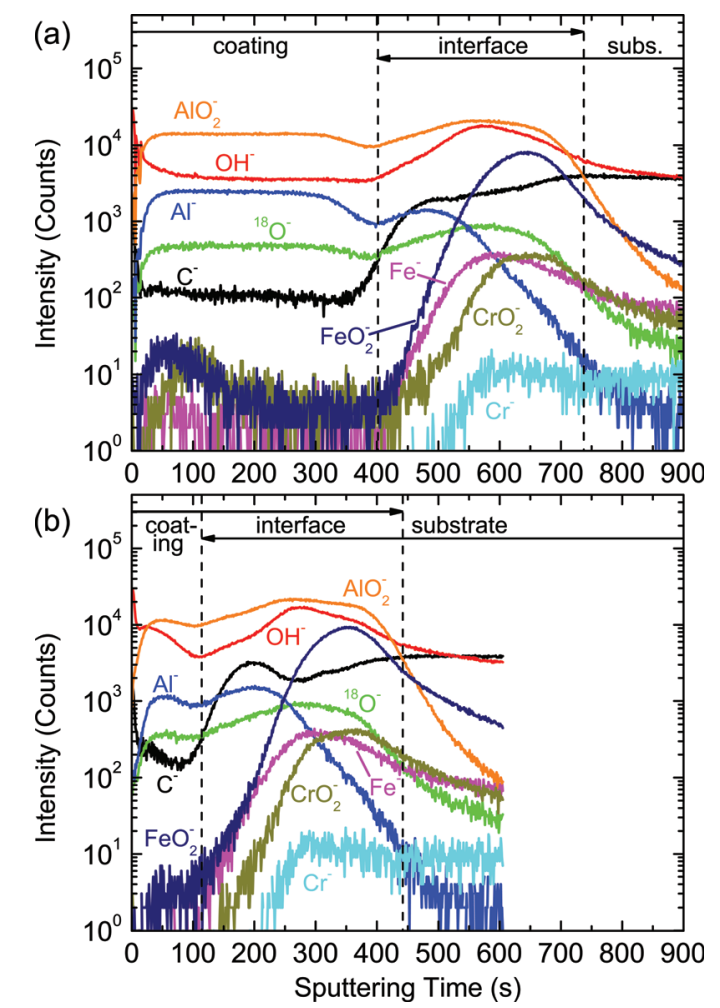

Figure 7. (Color online) ToF-SIMS depth profiles for $10 \mathrm{~nm} \mathrm{Al}_{2} \mathrm{O}_{3}$ deposited at $150^{\circ} \mathrm{C}$ on $100 \mathrm{Cr} 6$ using (a) plasma-enhanced ALD and (b) thermal ALD. modifications. The non-uniform ion profiles obtained for the thermal ALD film are a consequence of the higher sensitivity of this sample to environmental contamination.

NSS tests.-A thickness series, including films of nominally 10 , 20 and $50 \mathrm{~nm}$, was carried out on lapped (Fig. 8) and fine-ground (not shown) $100 \mathrm{Cr} 6$ steel. Where the $\mathrm{Al}_{2} \mathrm{O}_{3}$ thickness was nominally $10 \mathrm{~nm}$, significant rust was visible on all samples after $2 \mathrm{~h}$ NSS testing. A slight improvement was observed on increasing the layer thickness to $20 \mathrm{~nm}$ as, despite there being a substantial amount of visible corrosion, less rust was observed after $2 \mathrm{~h}$ than on the 10 $\mathrm{nm}$ sample. At $50 \mathrm{~nm}$, there was a clear improvement in the corrosion resistance, as the films were generally stable up to $4 \mathrm{~h}$ under NSS conditions. However, some slight corrosion was observed in specific areas, which is likely to be the result of defects in the film. For the temperature series $(10 \mathrm{~nm}$ thick films deposited by plasmaenhanced ALD, not shown), there was no significant difference between the visible corrosion resistance of the films deposited at all temperatures. Also for the $10 \mathrm{~nm}$ thick films, there was no clear difference in the quantity of rust observed for thermal and plasmaenhanced ALD, whereas for the $50 \mathrm{~nm}$ thick films, less rust was observed for the plasma-enhanced samples. The surface finish of the substrates also made no clear difference according to the NSS tests. Our coated substrates showed more corrosion within 24 h NSS testing than the nearest equivalent coating, which was $\sim 3 \mu \mathrm{m} \mathrm{NbO} x \mathrm{~N}_{y}$ on $100 \mathrm{Cr} 6$ steel. ${ }^{33}$ However, this is not unexpected as the thickness of our ALD was two orders of magnitude lower. Further comparison of NSS tests is difficult, as most procedures are carried out for $168 \mathrm{~h}$ or more before the quantity of rust is evaluated.

For the A12024-T3 substrates (Fig. 9), a small number of corrosion spots were observed after $2 \mathrm{~h}$ NSS testing, but significant rusting did not occur until after $24 \mathrm{~h}$. The film thickness, again, had some influence in the degree of corrosion protection, as the $50 \mathrm{~nm}$ thick films showed the most resistance. The deposition temperature did not make a visible difference to the amount of corrosion seen (not shown) and the difference between plasma-enhanced and thermal ALD was not so significant. It should be noted that the Al2024T3 substrates themselves are more resistant to corrosion than 100Cr6. Consequently, direct comparisons between the NSS results of the coated metal substrates are difficult to make. Therefore, using this method, it was not possible to ascertain whether the $\mathrm{Al}_{2} \mathrm{O}_{3}$ coatings provided the same level of corrosion protection on Al2024-T3 as they did on 100Cr6.

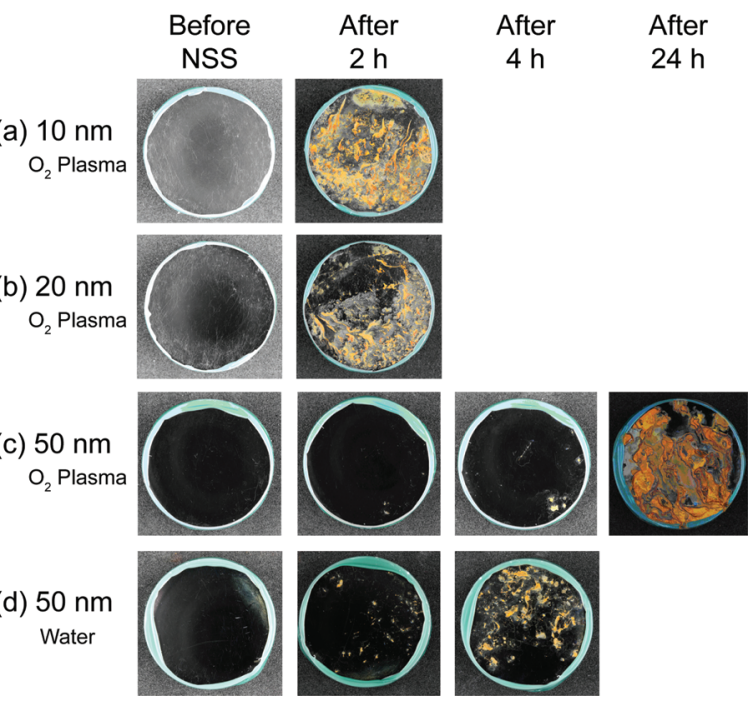

Figure 8. (Color online) NSS test results for lapped 100Cr6 samples coated at $150^{\circ} \mathrm{C}$ in (a) 10 , (b) 20 and (c) $50 \mathrm{~nm}$ thick $\mathrm{Al}_{2} \mathrm{O}_{3}$ deposited by plasmaenhanced ALD and (d) $50 \mathrm{~nm} \mathrm{Al}_{2} \mathrm{O}_{3}$ deposited by thermal ALD. 


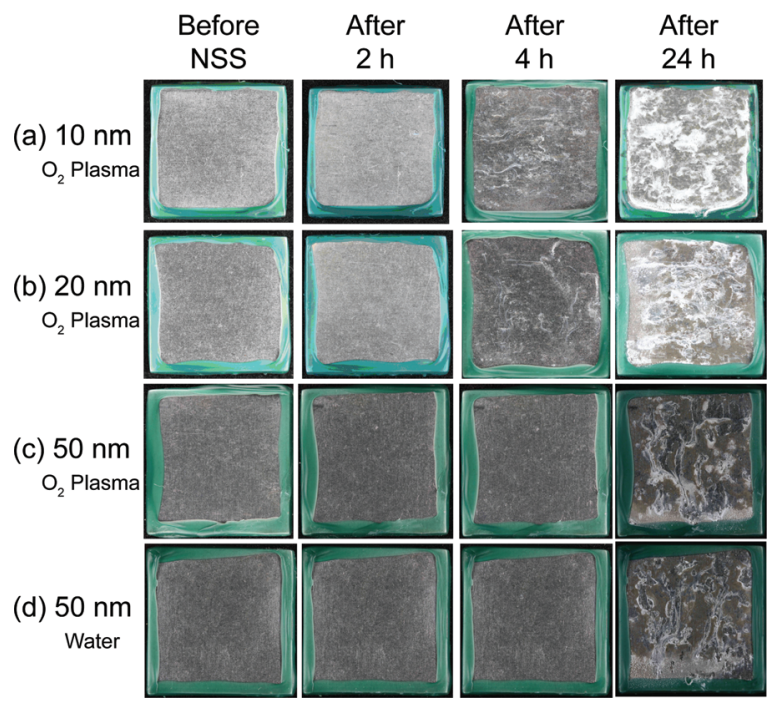

Figure 9. (Color online) NSS test results for fine-ground A12024-T3 samples coated at $150^{\circ} \mathrm{C}$ in (a) 10 , (b) 20 and (c) $50 \mathrm{~nm} \mathrm{Al} \mathrm{O}_{3}$ deposited by plasma-enhanced ALD and (d) $50 \mathrm{~nm} \mathrm{Al}_{2} \mathrm{O}_{3}$ deposited by thermal ALD.

Generally, the porosity of the films correlated well with the NSS results for both alloys, in that the thicker films were the least porous and provided the best corrosion protection. However, there were some discrepancies between the two techniques, whereby the porosity values for the $50 \mathrm{~nm}$ thick plasma-enhanced and thermal films were very similar yet the films deposited by plasma-enhanced ALD showed slightly better corrosion resistance. Also, the porosity data show a dependence on deposition temperature, whereas the NSS tests showed no change. This could be a feature of the measurement techniques themselves, as the CV measurements were taken in deaerated solutions, whereas, for the NSS tests, no special effort was made to exclude air, which could allow for faster corrosion.

\section{Conclusions}

10-50 nm thick $\mathrm{Al}_{2} \mathrm{O}_{3}$ thin films were applied to $100 \mathrm{Cr} 6$ steel and Al2024-T3 aluminium substrates as coatings for corrosion protection. The uncoated surface fraction determined from CV measurements showed that films deposited by plasma-enhanced ALD at $150^{\circ} \mathrm{C}$ were the least porous on $100 \mathrm{Cr} 6$, whereas on $\mathrm{Al} 2024-\mathrm{T} 3$ the films deposited at $50^{\circ} \mathrm{C}$ were the least porous. On both substrates, the $50 \mathrm{~nm}$ thick films had the best sealing performance, reaching a porosity lower than $0.5 \%$ on the $100 \mathrm{Cr} 6$ substrate. At $150^{\circ} \mathrm{C}$, the plasma-enhanced ALD and thermal ALD films were approximately equivalent where the nominal thickness was $50 \mathrm{~nm}$; however, for the $10 \mathrm{~nm}$ thick films, the plasma-enhanced method gave the lowest porosity because of better film nucleation in this case.

The improved nucleation by plasma-enhanced ALD was corroborated by cross-sectional TEM images, which showed that the 10 $\mathrm{nm}$ thick films deposited by thermal ALD were separated from the substrate, suggesting poor adhesion, whereas no void was observed for the films deposited using plasma-enhanced ALD. For the $50 \mathrm{~nm}$ thick films, ToF-SIMS depth profiles showed that the $\mathrm{OH}$ concentration was lower in the bulk of the films deposited by plasmaenhanced ALD than in those by thermal ALD. For the plasmaenhanced films, the $\mathrm{OH}$ concentration decreased with increasing film thickness, as the influence of the $\mathrm{OH}$-contaminated buried filmsubstrate interface was reduced. The surface $\mathrm{OH}$ concentration was higher for the plasma-enhanced films as a result of a higher density of reactive sites, which promoted surface hydroxylation from ambient moisture over time. For the $10 \mathrm{~nm}$ thick films, the difference was more substantial, with the thermal ALD films requiring a shorter sputtering time to reach the film-substrate interface, confirming that the films deposited by plasma-enhanced ALD were significantly denser at this thickness.

Neutral salt spray tests confirmed that the thickest films gave the best corrosion resistance $(>4 \mathrm{~h})$ and that the films deposited by plasma-enhanced ALD offered longer protection than those deposited by thermal ALD. There was no significant difference observed for the $10 \mathrm{~nm}$ thick films deposited at different temperatures. Overall, the application of $\mathrm{Al}_{2} \mathrm{O}_{3}$ thin films to industrial alloys improved their resistance to corrosion. For the thicker $(50 \mathrm{~nm})$ films, the material deposited by both ALD techniques provided the most protection, with the films deposited by plasma-enhanced ALD showing the smallest quantity of rust after $4 \mathrm{~h}$ NSS testing. For the thinner $(10 \mathrm{~nm})$ films, plasma-enhanced ALD gave films with a lower porosity and better nucleation behaviour, showing that plasmaenhanced ALD is a promising method with which to deposit ultrathin films for the sealing and corrosion protection of precision parts.

\section{Acknowledgments}

The research leading to these results has received funding from the European Community's Seventh Framework Programme (FP7/2007-2013) under grant agreement number CP-FP213996-1 (CORRAL). The authors thank W. Keuning, C. A. A. van Helvoirt, J. J. A. Zeebregts, and M. J. F. van de Sande for their technical assistance, support and advice.

Eindhoven University of Technology assisted in meeting the publication costs of this article.

\section{References}

1. R. Bayón, A. Igartua, X. Fernández, R. Martínez, R. J. Rodríguez, J. A. García, A. de Frutos, M. A. Arenas, and J. de Damborenea, Tribol. Int., 42, 591 (2009).

2. J. E. Gray and B. Luan, J. Alloys Compd., 336, 88 (2002).

3. H.-C. Lee, Y.-H. Hwang, and T.-G. Kim, Eng. Failure Anal., 10, 77 (2003).

4. G. Bierwagen, R. Brown, D. Battocchi, and S. Hayes, Prog. Org. Coat., 67, 195 (2010).

5. A. Akhtar, J. Y. Wong, G. S. Bhuyan, C. T. Webster, D. Kung, L. R. Gambone, N. Neufeld, and W. J. Brezden, NDT \& E Int., 25, 115 (1992).

6. J. H. Smith, M. D. Rana, and C. Hall, J. Pressure Vessel Technol., 125, 177 (2003).

7. M. D. Rana and J. H. Smith, J. Pressure Vessel Technol., 126, 202 (2004).

8. D. Martínez, R. Gonzalez, K. Montemayor, A. Juarez-Hernandez, and G. Fajardo, Wear, 267, 255 (2009)

9. N. L. Lee, G. B. Fisher, and R. Schulz, J. Mater. Res., 3, 862 (1988).

10. M. H. Ding, B. L. Wang, L. Li , and Y. F. Zheng, Surf. Coat. Technol., 204, 2519 (2010).

11. T. Goto, C.-Y. Guo, H. Takeya, and T. Hirai, J. Mater. Sci., 27, 233 (1992).

12. J. Perez-Mariano, K. H. Lau, E. Alvarez, R. Malhotra, M. Hornbostel, G. Krishnan, and A. Sanjuro, Surf. Coat. Technol., 202, 2794 (2008).

13. H.-R. Stock, H. Berndt, and P. Mayr, Surf. Coat. Technol., 46, 15 (1991).

14. J. R. Sobiecki, P. Mańkowski, and T. Wierzchoń, Vacuum, 68, 105 (2003).

15. K. Gammer, M. Stoiber, J. Wagner, H. Hutter, R. Kullmer, and C. Mitterer, Thin Solid Films, 461, 277 (2004).

16. S. M. George, Chem. Rev., 110, 111 (2010).

17. W. M. M. Kessels, S. B. S. Heil, E. Langereis, J. L. van Hemmen, H. C. M. Knoops, W. Keuning, and M. C. M. van de Sanden, ECS Trans., 3(15), 183 (2007).

18. H. B. Profijt, S. E. Potts, M. C. M. van de Sanden, and W. M. M. Kessels, J. Vac. Sci. Technol. A, Submitted.

19. W. M. M. Kessels, H. B. Profijt, S. E. Potts, and M. C. M. van de Sanden, Atomic Layer Deposition of Nanostructured Materials, Wiley-VCH, Weinheim, Germany, In press.

20. S. E. Potts, W. Keuning, E. Langereis, G. Dingemans, M. C. M. van de Sanden, and W. M. M. Kessels, J. Electrochem. Soc., 157, P66 (2010).

21. E. Langereis, J. Keijmel, M. C. M. van de Sanden, and W. M. M. Kessels, Appl. Phys. Lett, 92, 231904 (2008).

22. J. L. van Hemmen, S. B. S. Heil, J. H. Klootwijk, F. Roozeboom, C. J. Hodson, M. C. M. van de Sanden, and W. M. M. Kessels, J. Electrochem. Soc., 154, G165 (2007).

23. R. Matero, M. Ritala, M. Leskelä, T. Salo, J. Aromaa, and O. Forsén, J. Phys. IV, 9, 493 (1999)

24. X. Du, K. Zhang, K. Holland, T. Tombler, and M. Moskovits, Appl. Opt., 48, 6470 (2009).

25. S.-H. K. Park, J. Oh, C.-S. Hwang, J.-I. Lee, Y. S. Yang, and H. Y. Chu, Electrochem. Solid-State Lett., 8, H21 (2005).

26. M. D. Groner, S. M. George, R. S. McLean, and P. F. Carcia, Appl. Phys. Lett., 88, 051907 (2006)

27. A. P. Ghosh, L. J. Gerenser, C. M. Jarman, and J. E. Fornalik, Appl. Phys. Lett., 86, 223503 (2005). 
28. E. Langereis, M. Creatore, S. B. S. Heil, M. C. M. van de Sanden, and W. M. M. Kessels, Appl. Phys. Lett., 89, 081915 (2006).

29. E. Langereis, S. B. S. Heil, H. C. M. Knoops, W. Keuning, M. C. M. van de Sanden, and W. M. M. Kessels, J. Phys. D: Appl. Phys., 42, 073001 (2009).

30. W. Tato and D. Landolt, J. Electrochem. Soc., 145, 4173 (1998).
31. M. D. Groner, F. H. Fabreguette, J. W. Elam, and S. M. George, Chem. Mater., 16, 639 (2004).

32. H. C. M. Knoops, E. Langereis, M. C. M. van de Sanden, and W. M. M. Kessels, J. Electrochem. Soc., 157, G241 (2010)

33. M. Fenker, H. Kappl, P. Carvalho, and F. Vaz, Thin Solid Films, 519, 2457 (2011) 